\title{
A "Little Death": The Near-Death Experience and Tibetan Delogs
}

\author{
Lee W. Bailey, Ph.D. \\ Ithaca College
}

ABSTRACT: A phenomenon remarkably like the near-death experience has been uncovered in Tibetan culture, aside from the so-called Tibetan Book of the Dead (Thurman, 1994). Anthropologists have gathered accounts of contemporary and historical cases of remarkable people called delogs. Seemingly dead for several hours or days, these people revive spontaneously and tell detailed accounts of otherworldly journeys. Their journey accounts contain elaborate versions of Buddhist otherworldly landscapes and characters, emphasizing the moral and spiritual teachings of Tibetan Buddhism. These delogs are a bridge between contemporary near-death experiences and ancient shamanic practices.

KEY WORDS: delog; shaman; Tibet; Buddhism; NDE; near-death experience.

Accounts of people called delogs, dying and coming back to life, are well-known in Tibetan culture, and have been sporadically mentioned in Western studies. Now Euro-American researchers are translating texts and interviewing living delogs. Reviving after appearing to be dead for hours or days, these remarkable people report fantastic journeys into an otherworld filled with dramatic Buddhist figures judging and punishing or rewarding the dead.

The Tibetan word is transliterated 'Das log, and variously spelled in different languages, but pronounced "DAY-log." I have adopted the spelling of the latest English book entitled Delog, about Dawa Drolma, translated by her son (Drolma, 1995). Some regional dialects use other colloquial names.

In typical accounts of delogs, as young persons they have been gravely ill. High in the Himalayan mountains, lying in a small hut, they seem to be dead to those grieving around them. But instead, they later report,

Lee W. Bailey, Ph.D., is Associate Professor of Religion and Culture in the Department of Philosophy and Religion at Ithaca College. Reprint requests may be addressed to Dr. Bailey at Ithaca College in Ithaca, New York 14850; e-mail: bailey@ithaca.edu. 
they had risen up above their bodies, which then they did not recognize as their own. Theirs is an archaic example of a mystical experience of the after-death state. Delog deaths are an extraordinary tradition in Tibetan culture, strikingly akin to the near-death experience (NDE).

Next these persons' dazed souls enter into a raucous hereafter, guided by their personal deity. They are taken to meet the horrifying Lord of Death himself. They are led on a shocking tour of Hell, where they see numerous condemned souls miserably suffering punishments befitting their sins, such as the nun who hears the unending cries of her own baby whom she murdered. The anguished sinners send urgent messages back to the living, begging family to do rituals to aid in their salvation and exhorting others to live an ethical life. The astonished travelers meet deceased parents and travel to paradise. Returning to the throne of the Lord of Death, they observe the dreadful judgment of souls with a bridge, a scale, or a mirror. They themselves are judged and given a message to send back. Their consciousnesses return to their bodies on earth. They deliver the various messages and exhort all to practice their Tibetan Buddhist religion faithfully.

Such accounts of the Tibetan delogs are astoundingly akin to what we in the West call near-death experiences. But there are revealing differences with important implications. Sogyal Rinpoche discussed the delog phenomenon in The Tibetan Book of Living and Dying (Sogyal, 1993). He reported that "In Tibet this was an accepted occurrence, and elaborate methods were devised for detecting whether déloks were fraudulent or not" (Sogyal, 1993, p. 331). Earlier studies include articles by Lawrence Epstein (1982), Kenneth Ring (1993), and Christopher Carr (1993). I will discuss their views below.

There are historical records of delogs and contemporary studies of living delogs. Usually women, delogs have a revered place in Tibetan popular religion, although they may be neglected by some Buddhists. Historically, Buddhism was introduced to Tibetan culture from India in the 7th century C.E. The Indian master Padmasambhava was then invited by the King of Tibet in the 8th century. In order to bring Buddhism to Tibet, Padmasambhava had to contend with the native Bön religion, and some of the resulting traditions spiritualized these earlier tribal shamanic practices. The first Buddhist monastery was founded in 775 C.E. Later the leadership focused on the Dalai Lama, who was seen as the bodhisattva Avilokiteshvara in human form, living in the Potala palace in Lhasa. Although the delogs remained on the fringe of rural, archaic, Himalayan tradition, they absorbed much of the new Buddhism.

Following Epstein, the most notable anthropologist to study delogs was the French anthropologist Françoise Pommaret (1989), the first 
Westerner to do a book-length study, Les revenants de l'au-dela dans le monde Tibetain: Sources littéraires et tradition vivante [Those who return from the hereafter in the Tibetan world: Literary sources and living tradition]. She traveled often to the Himalayan highlands just south of Tibet, still accessible despite the 1959 Chinese invasion of Tibet, and part of Tibetan culture. In Nepal and Bhutan she discovered historical records of ten delogs from the 11th to the 20th century. She then interviewed a delog in a village in Nepal and three in Bhutan.

The other new book about a delog is the English account of Delog Dawa Drolma, who lived in Tibet around 1900 to 1941 and recorded her dramatic journeys to the hereafter with the aid of a scribe. Her book Delog: Journey to Realms Beyond Death was translated into English in 1995. Wandering Himalayan storytellers (mani pa) are also known for retelling these incidents (Pommaret, 1989). Delog accounts became a Tibetan literary genre by the 16th century, but they are just now reaching a global audience.

\section{Historical Texts}

Pommaret's studies of historical delog texts from the 12th to the 20th centuries included a notably detailed story of a delog whose biography was based on a 17th-century manuscript (Thimphu, 1980). This manuscript, like many others, was from a private collection studied by Pommaret. Since so many texts were carried from Tibet by exiles when the Chinese invaded, libraries are incomplete, although the Tibetan $\mathrm{Li}$ brary of Works and Archives in Dharamsala, India, now houses at least a dozen accounts of delogs. In this case, the text (Thimphu, 1980) was a 193-page book, but has no colophon giving more publication details. The 17th-century original date was deduced by Pommaret (1989) from other references.

\section{Chos 'dzom ("Chonzom”)}

Sangs Rgyas chos 'dzom of Bhutan lived soon after 1650. As a 12year-old girl, she said that the bodhisattva Avilokiteshvara told her that she had seven days to travel in the 18 realms of the hereafter. Feeling blessed, she was taken to his paradise, Mount Potala. Returning home, she heard her immensely sad parents say that she was dead. She saw her own corpse, but cried because it was a pig! She met her yi dam (personal divinity) who guided her, saying, "Do not be attached to your body of illusion; lift your spirit towards the essence of things. Follow me." He 
took her hand, assuring her with the classic Buddhist mantra "Om mani padme hum" "Hail, the jewel in the lotus") (Pommaret, 1989, p. 32).

Taken to the first realm between incarnations (bardo), she witnessed the terrible suffering of the dead. Vast numbers of people were experiencing painful retribution matched to their sins. But she and her $y i$ dam entered a place of pure white light. All the mountains, valleys, and bodies of the dead were glowing pure white. A dazzling, white divinity had a shocking white face. Soon she saw more terrifying divinities of yellow, red, and green, and she fainted. Revived, she traversed a bridge over an ocean of fire, where she witnessed an ox-headed acolyte of the Lord of Death beating some tied-up victims for having eaten meat. Further on, she saw several dazzling beams of light, leading to regions of various Buddhas, gods, demi-gods, humans, and animals.

But first she had to meet the horrifying Lord of Death, Yama. Protected by her personal divinity, she entered his palace and trembled as she saw his ugly, red face, wide-eyed and fanged. Wearing a tiger skin, skulls, and flames, he held the fateful mirror of existence, a sword, and water. His frightening voice rumbled like a thousand dragons. He was attended by numerous ugly, animal-headed acolytes and a nasty, little, black demon holding black pebbles signifying the sinful deeds of each poor person to be judged. But a white deity held white pebbles that would weigh against the black deeds. This vast army of beasts was chanting "execute! execute!" or whacking off the heads of the weeping victims.

Our horrified traveler fainted, but was revived and told by her protective guide that all these suffering ones were receiving their retribution for having killed while on earth. But the faithful would not suffer so. She was told by the Lord of Death that, according to the mirror of existence, she had been dead seven days, and that it was now time for her to return to the land of the living. Her task was to be a messenger between the living and the dead. Furthermore, she was told that she was the incarnation of Avalokiteshvara Mahakaruna and she was to explain to humans the bardos and the 18 hells in detail without hiding anything. She was to give grave warnings from the Lord of Death about punishments for such moral trespasses as infanticide, adultery, greed, black magic, and war. He urged serious religious practices, such as meditation: "You must inspire all people to practice religion" (Pommaret, 1989, p. 65). He foretold that she would return for her final death at age 50, but she must hurry back, because her family was about to cremate her corpse.

Chos 'dzom immediately returned to her village, Za chu sgang, and saw her corpse. She then lost consciousness and a man said that the 
heart of her corpse was now warm. She awoke and soon the entire village was exclaiming: "The girl has returned from the land of the dead" (Pommaret, 1989, p. 66). Some skeptics accused her of not telling the truth, but many gathered around her urging her to tell what she saw in the bardo. She told of her journey while dead for seven days, seeing the 18 hells and all the paradises. Finally, she stressed that the message of the Lord of the Dead is more joyous and precious than gold. Her experience demonstrates the typical elements of the delog phenomenon.

\section{Living Delogs}

In addition to the studying historical texts, Pommaret interviewed several living delogs. She interviewed at least four living delogs in the 1980s. In Bhutan, in the village of Wamrong, she interviewed a thin, wrinkled elderly woman, Rizing Gyelmo, who was surprised that strangers would be interested in her. In 1982, she was 78 years old. She had been married to a peasant and had four children, all now married with children. Her husband had died in 1972, and she now lived with two sisters. Rizing reported that she "died" first at the age of five months, after a grave illness. She "died" and returned later, but at the age of 13 she had the revelation that she was a delog, and an incarnation of the bodhisattva Avalokiteshvara. She emphasized that only in the old days did the delogs die for several days. Now she was one of those who die for only a few hours, so she should actually not be called a delog, but a nyin log, meaning "returning in one day." Pommaret (1989) witnessed her during a three-hour séance when she chanted a very long call to the dead to come forth.

A second delog, found in the village of Khamdang, was named Karma Wangzom. As an infant she had been mistreated by a drunken father, she said, and had "died" several times. At the age of 13 she became a delog. She stopped eating garlic, onions, pork, fish and eggs. She began to "die" on fasting days, the 10th, 15th, and 30th of each month. She would "die" for three or six hours, beginning at 6:00 in the morning. On her return she sang the messages from the dead and the Lord of the Dead. She said that she had not received particularly religious teachings before becoming a delog. Some villagers said that this delog had suffered from epilepsy but had succeeded in controlling it. This raises the question of the role of illnesses such as epilepsy in delog-like traditions. In his classic study of shamanism, Mircea Eliade (1951) discovered that illnesses such as epilepsy were often characteristic of tribal 
spiritual healers. Among the Siberian Voguls, for example, "the future shaman ... is sometimes even subject to epileptic seizures, which are interpreted as meetings with the gods" (Eliade, 1951, p. 15). Or, "Often when the shaman's or medicine man's vocation is revealed through an illness or an epileptoid attack, the initiation of the candidate is equivalent to a cure" (Eliade, 1951, p. 27). Eliade concluded:

Whether he is chosen by gods or spirits to be their mouthpiece, or is pre-disposed by this function by physical defects, or has a heredity that is equivalent to a magico-religious vocation, the medicine man [or woman]... has more direct relations with the sacred.... Infirmity, nervous disorder, spontaneous vocation, or heredity are so many external signs of "choice," an "election." (1951, p. 31)

So to Eliade, a delog having epilepsy would not be discrediting. It would likely be a mark of being called into the sacred realm of her vocation.

In the Bhutanese village of Maidung an 18-year-old girl lived on a prosperous farm and dressed in a Tibetan robe, indicating a religious vocation. She told Pommaret that she was named Choekyi Wamgmo by the Lord of the Dead. She had "died" often as a child, and at age 14 she proclaimed herself a delog. Like others, she was considered to be the reincarnation of an earlier delog. According to the local custom of sororal polygyny, she had a daughter by her sister's husband. She did not wish to live a conventional married life, so she made herself a stone retreat hut where she lived with her child, devoting herself to the religious life. Having a daughter, she said, she was unable to visit certain parts of the otherworld. Now she "died" on the 10th, 25th, and 30th of the lunar month. Many people from the region came to her for advice. Some believed that her "deaths" resembled epileptic crises.

Pommaret (1989) learned that various delogs have been reported to have a cold heart and a cold body, or a slow heartbeat during their journeys to the land of the dead. They then return with news of the deceased for their families. One man from Tongsa, in central Bhutan, who was blind, was a renowned delog who "died" on the 15th and 30th of each month and returned, reporting the news of people's dead parents, the causes of illnesses, and of the future. Pommaret (1989) included photographs of some of these delogs in her book.

In the Bhutanese valley of Chumey à Bumthang in 1977-1978 a boy was born to a family of poor peasants. His mother later died and his father remarried. The unhappy boy ran away to the monastery of Petsheling à Bumthang Choekhor, to join an uncle. There he fell ill and "died" in 1985 . He was returned to his family where he "died" a second 
time and reported that he saw his mother. His father called his vision demonic and beat him, but the villagers declared the boy a delog. He was sent to the monastery at Nyimalung, where he studied briefly, but the little 8-year-old failed to persuade the people outside his village of the validity of his experience, so he was sent home to become a cowherd (Pommaret, 1989).

\section{Influences Behind the Delog Accounts}

Historically, large portions of Hinduism were adopted by Buddhism, especially in the area of cosmology, so it is no surprise that their pictures of the infernal realms are very similar (Pommaret, 1989). Many Hindu details, such as the names of various hells, and the image of the copper cauldrons for cooking the condemned, can be found the Buddhist Traité de la Grand Vertu de Sagesse, from around the $3^{\text {rd }}$ century A.D. (Pommaret, 1989). Similarly, the archaic pre-Buddhist Bön tribal traditions may have also absorbed some older Hindu traditions.

The way certain sins are highlighted and their punishments are made to fit the sin reflects the issues of concern in traditional Tibetan society. For example, for practicing black magic, the punishment is to have a magic dagger plunged into the body. The delogs teach the Buddhist view that the families of the dead can help save them ritually by offering prayer flags, food, and water, and by decorating statues and reciting sacred texts. The delog scene of the judgment by the Lord of the Dead Yama Dharmaraja reflects the background of Hindu Lord of the Dead, Yama, and his acolytes, the black and white pebbles, and the mirror of truth. Retributive punishment may be cumulative, but it is temporary, and rebirth is certain, affirmed by the classic Hindu and Buddhist doctrines of reincarnation and karma.

Other details have a more uniquely Tibetan background, such as the tradition of the god and the demon born at the same time as a person (Pommaret, 1989). Although the traditional accounts of the delogs certainly has roots in the archaic Bön tribal religion in Tibet prior to the Buddhist influence, the literature of the delog now largely reflects much orthodox Buddhism. Nevertheless, the delogs tend to be more part of the rural, popular religion than the highly literate monastic culture. The high goals of the monasteries strive to raise the consciousness of students above the fear of punishment and direct them toward compassion and wisdom, detachment and meditative insight. This is partly why the monasteries do not encourage the delogs. They are acknowledged, however, as part of the larger spiritual community. 
The delog focus on death is part of the considerable preparation for death in all of Buddhism. The so-called Tibetan Book of the Dead [Bardo Thödol] (Thurman, 1994) is part of a large death literature in which students are taught to meditate on impermanence (Govinda, 1960). Subsequently, one's state of mind at the time of death is considered vitally important, because it can determine what kind of rebirth a person will have. "Strongly negative thoughts at the time of death-anger, resentment, or hatred, etc. - this can erase the effects of a lifetime of virtuous conduct and lead to a rebirth characterized by suffering" (Powers, 1995 , p. 305). Conversely, positive thoughts can reverse a lifetime of negativity.

The descent to the underworld is one of the most universal themes of visionary experiences, and in India and China the literature on this theme is considerable. In Tibet, the main forms are (1) the savior-figure, such as the famous disciple of Buddha, Maudgalyayana (Pommaret, 1989 ) or the divine Alvalokiteshvara, or (2) the human delog. A common Chinese theme is the return of an ordinary dead person to life due to the error of an infernal bureaucratic functionary (Pommaret, 1989). A theme parallel to ancient Iranian religion is the bridge over which the dead must cross. In ancient Persian Zoroastrianism it is called the Chinvat bridge, which is wide and easy for believers to cross, but narrow as an upright razor for sinners (Pommaret, 1989).

Tibet may have been influenced by traditions of shamanic otherworld journeys from the Turkish-Mongolian culture. One text reported that "a slave of the Mongols had been plunged for seven days into a hypnotic sleep before being interrogated on his visions" (Pommaret, 1989, p. 99). Sleep was sometimes described by the Turkish Mongols as a "little death," as it is in Tibetan culture.

\section{Comparing the Delog and the Near-Death Experience}

Pommaret (1989) outlined a typology of the delog adventure that can be contrasted with many typical elements of the contemporary Western near-death experience.

\section{Presentation of the Delog}

First, the recitation of the delog story always begins with a short prayer. The delog is presented by name, parents' names, and birthplace. 
For example:

In Bhutan in the western province of Bkra shis sgang, in a place called 'Phangs ri gsang gdun, lived a man Bsod nams don grub and a woman T she dgang rgyal mo who had all the signs of the dakini Ye shes mtsho rgyal. They had a daughter Sangs rgyas chos 'dzom who was an incarnation of the boddhisattva Avalokiteshvara. (Pommaret, 1989, p. 67)

Comparing this to contemporary near-death studies, we can see that NDEs focus on the individual. Western individuality minimizes such concern for parents, birthplace, and the atmosphere of an ancient tribal society oriented to land and family. So by contrast, NDEs in a Western industrial society are more likely to focus on individuals and their lives than on parents and birthplace. Nor are NDEs likely to have so strong a religious emphasis as to begin with a prayer. And Westerners would not dare say that the near-death survivor was an incarnation of a divine figure.

\section{Premonition Dream and Death}

Some delogs experience a premonition dream and there may be an allusion to their intense desire to practice the religion of their ancestors. One premonition dream of Byand chub send ge went like this:

A white boy advised me not to eat the food that people were eating. I followed him and he sat in the center of a lotus of a thousand petals. $\mathrm{He}$ was surrounded by thousands of others. All recited the mantra $\mathrm{Om}$ mani padma hum (Hail, the jewel in the lotus). He gave me a liquid like milk, saying that it was nectar. And he gave me a crystal rosary and said: "Daughter... I am Avalokiteshvara" and he disappeared like a rainbow. (Pommaret, 1989, p. 68)

Then an illness, often quite sudden, leads to the death of the delog.

This dream centers on the symbolism of a Buddhist divine child, seated in the midst of a huge Buddhist lotus. He is the jewel in the lotus of the classic mantra. He is Avalokiteshvara, the bodhisattva of compassion as a child. His appearance in a dream is interpreted as a prelude to a journey to another realm. For Buddhists all reality is ultimately mind, so dreams could possibly foretell later events. But while some Westerners may be interested in dream interpretation, few would take a dream to be a premonition of literal events such as a neardeath experience. Influenced more by Sigmund Freud and Carl Jung, 
a Western view would more likely see such dreams only symbolically. Jung would see the child as the divine within, the Self.

\section{Realization of Death}

At first, the delogs may not realize that they are dead, when the spirit separates from the body, leaving it seeming like an animal in the delog's clothing. As the disembodied spirit roams about the home, the delog may not understand why the rest of the family is acting so strangely and unresponsive to the delog's efforts at communication. The experience of Gling Bza' chos skyid is typical:

Then when I saw my own bed, there was the cadaver of a big pig covered with my clothing. My husband and my children and all the neighbors of the village arrived and began to cry... They began to prepare for a religious ceremony and I thought, "What are you doing?" But they did not see me and I felt abandoned. I did not think that I was dead. (Pommaret, 1989, p. 70)

Finally, the delog realizes that she or he actually is dead.

Now the experience of the delog begins to sound more like a typical near-death experience. The out-of-body experience and the failure to realize one is dead are familiar, as well as feeling perplexed when people do not see or hear one's floating soul. Some also feel no attachment to their dead bodies below, and are surprised to discover that the corpse below is theirs (Gibbs, 1997). Of course, the big difference in the delog experience is that of seeing the body below as a pig, which is quite unlike a typical NDE. The pig is a Tibetan Buddhist symbol of ignorance and delusion, pictured in mandalas such as the Wheel of Life (Blofeld, 1970).

\section{First Contact with the Other World}

Next the delogs have their first contact with the other world, the realm between life and death, or bardo, which seems like a countryside. They likely meet frightening acolytes of the Lord of Death. They frequently meet their familiar protective divinity, the yi dam, who will be their mentor in the infernal realms. In most accounts, the delog crosses a bridge over an enormous river, marking the entry into the other world.

When Chos 'dzom met her protective deity (yi dam) and guide, he said, "Don't you know that you are dead? Don't show attachment to your body of illusion; lift your spirit towards the essence of things. Come where I will lead you" (Pommaret, 1989, p. 32). Then she met those terrifying 
creatures crying "execute! execute!" but was protected by her yi dam and her mantra.

The spiritual guide is sometimes part of the Western NDE, especially in the medieval versions, where angelic protectors guide the perplexed wanderers (Zaleski, 1987). Ring pointed out that "we have in our own Western tradition NDEs that are, almost point for point, the exact equivalent of the das-log experience in Tibet. I'm referring to the medieval period" (1993, p. 80). Dante's Divine Comedy (Alighieri, 1939/14th century) was the culmination of this tradition. In it he was first guided by the literary Virgil, then the more transcendent Beatrice, whose "eyes shone brighter than the stars" (Alighieri, 1939/14th century, "Inferno," II: 55). In the "Inferno," Beatrice said: "Only those things should be feared that have power to do us ill, nothing else, for nothing else is fearful, and I am made such by God of His grace that your misery does not touch me nor a flame of the fires here assail me" (Alighieri, 1939/14th century, "Inferno," II: 89-93).

Buddhists are urged as part of their basic education in life to develop a relationship with their individual guiding deity, so they will recognize it at death. But often contemporary NDErs are on their own, which may be the source of innumerable subsequent difficulties in adjustment. The bridge provides a border between life and death. In Western NDEs, however, is it more likely a point of no return, whereas for delogs, it is not.

Most Western religions, in the context of Western materialism, now struggle to transmit a sense of the transcendent. By contrast, Tibetan Buddhism assumes the greater reality of the vast undying transcendent spaciousness surrounding earthly life. In Buddhist belief, this realm of light is reality, and the earthly life, with its brief impermanence and suffering, is ultimately an illusion. This is one of the most important differences between the two religions.

\section{Description of the Infernal Realms}

Next the delog is taken on a voyage into the infernal realm to observe and understand the tortures of karma. In an initial appearance before the Lord of the Dead, the delogs and their guides are invited to tour the land of the unliving and then return before his throne. Often they soon meet a familiar person, such as a parent or brother, whose transgressions and punishments are explained. Urgent requests for living survivors to perform rituals to save the suffering are frequent. For example, Karma dbang 'dzin met her deceased brother, who was forced to 
become a cowherder. Having not studied his religion and learned right from wrong behavior, he stooped to some wickedness in life and so he must now suffer. He begged her to perform some rituals to assist in his deliverance, including serving tea at the monastery, copying and reading religious texts, and offering a hundred thousand sacrificial gifts to meditating sages (Pommaret, 1989). Some delogs may observe scenes of deliverance; some travel in the higher realms of the gods, paradises, buddhas, and bodhisattvas; while others venture into the lower realms of animals being reincarnated.

While travelers in a Western NDEs may meet known persons, there is little concern for the living doing rituals to aid the dead, outside the Mormon faith. In the West the request for the living to perform rituals to save a dead individual from punishment is largely a historical memory of medieval tradition. Some contemporary NDEs, however, may be greatly concerned with collective moral issues, such as Dannion Brinkley's prophetic visions of ecological and nuclear disasters (Brinkley and Perry, 1994). Individuals struggling with their own moral and spiritual issues, Brinkley saw, simply experience the pain that they caused others until they learn. They do not typically encounter the terrifying scenes of punishment pictured in delog experiences.

\section{Reappearance Before the Lord of the Dead}

The sixth theme in the journeys of the delogs is the reappearance before Yama, the observation of several judgments, and the judgment of the delogs themselves. An important factor is that they have accumulated sufficient good karma in their previous lives so that the Lord of Death sends them back to live in their old bodies. Finally Yama confers on the delog a long list of warning messages for the living. One of the longest was that delivered to Kun dga' rang grol, including:

Transmit this message to lamas:... Let them attempt to be perfect guides for human beings... Transmit this message to government functionaries: do not give without reason illegal punishments, for it is a reason to fall into hell... Transmit this message to nuns: renounce domestic tasks and force yourselves to practice religion.... Transmit this message to the mani pa of the world: convert the royalty to Buddhism but do not exaggerate your stories... Transmit this message to the laity: respect your parents, offer food... be sincere, do not beat animals; if you look inside yourselves there are demons... Live so that you will have no shame in my presence. (Pommaret, 1989, p. 77) 
Why do these concerns with moral judgment and specific admonitions to good behavior seem so foreign to contemporary NDEs? I suggest that it is because they represent two different types of cultural development. First of all, most of the people who seek out the delogs are not literate, but are simple peasants in the rural Himalayan regions. Valued education was brought to the mountains by the Buddhist monasteries, and moral lessons are very explicit in that education. In Western mass education, many basic moral lessons are more implicit. But even secular education teaches honesty, truth, fairness, civic responsibility, the value of law, democracy, and other moral teachings originally taught by religions, though, of course, not by all religions.

Secondly, Western culture has absorbed and spread many of the moral lessons of its religions through volunteer institutions such as the Red Cross and through government programs such as welfare. When successful, mass education has been the bridge for much of this development. The mental responsibilities and self-control cultivated in mass education make the forceful, fearful admonitions to personal morality of old religions less necessary. Through mass education, literate understanding increasingly replaces fear of hell as a moral motive. The themes of an NDE inevitably reflect the collective issues of one's culture.

\section{Return to Earth}

When the Tibetan delog returns to life, and awakens very thirsty after seven days or so, the person in charge of the cadaver is generally terrified. Some people believe the adventures of delogs, but others see in them charlatans or even demons. Finally, delogs are usually recognized as holy persons, and they spread their experiences throughout the region, exhorting all to abandon any ultimately punishable behavior and practice Buddhism wholeheartedly. Their stories are then written down by a scribe (Pommaret, 1989).

There is no shortage of skepticism in the rural Himalayan region. The response of some that the delog is a charlatan or demon sounds rather familiar to Western students of NDEs. In the West, scientific skeptics offer the charlatan or the hallucination argument, while religious fundamentalists offer the demon or the Satan-in-disguise-tricking-you accusation.

Survivors of NDEs in the West may occasionally be seen as holy persons, but many others, including survivors themselves, reject any such suggestions. Today saints such as Mother Teresa are rare in the West. 
Fewer people in industrial societies enter on a traditional path of holy vows, because the focus is on overcoming suffering through technology. Consequently an NDEr does not so easily undertake a traditional spiritual practice and join a monastery or convent, as was more common in medieval cultures. This leaves many NDE survivors struggling without the communal support and spiritual patterns to expand upon their experiences. Writing down the story remains an important step everywhere, however, even if the survivor needs the assistance of a scribe, in the West taking the form of a professional writer or editor.

\section{Fiction or History?}

Are the delog stories simply a genre of Tibetan literary fiction rooted in exaggerated oral tradition? Or are they authentic historical accounts of survivors of near-death experiences? Based upon her interviews with living delogs, Pommaret concluded that the delogs are actual historical persons, not just fictions:

... le fait que des 'das log existent aujourd'hui prouvent définitivement qu'à la bas des biographies, il y a non pas des fictions littéraires mais des personnes réelles [the fact that the delogs exist today proves definitively that at the base of the biographies there are not literary fictions but real persons]. (Pommaret, 1989, p. 82)

The story of the delog Dawa Drolma provides further evidence for the historicity of delogs. Up to 1941 she underwent several classical journeys into the underworld. Her son, now living in the United States, testified that at times, "For five full days she lay cold, breathless, and devoid of any vital signs, while her consciousness moved freely into other realms" (Drolma, 1995, p. vii). Her experiences gave her great spiritual authority. A great lama, Tromge Trungpa, witnessed her corpse coming back to life. Once, upon waking up, she accurately knew the location of some buried coins, which she could not possibly have known unless told by deceased persons in the other world (Drolma, 1995, p. ix). These reports correspond with contemporary cases of NDE survivors showing no signs of life (Bailey and Yates, 1996) and awakening knowing new information, such as the famous sneaker perched on the unlikely hospital ledge (Sharp, 1995). The range of time that a delog is unconscious varies greatly, from a few hours to several days. The range of consciousness also varies, from a mild trance to apparent death, with no breathing and no vital signs. 


\section{Interpretation}

How can we interpret these phenomena? First we must ask what the native Bhutanese mean when they say someone "dies." Pommaret (1989) explained that the Tibetan verb used, shi ba, has two senses: one meaning is a clinical death as defined by Western medicine; the second meaning is the departing of the principle of consciousness from the bodily envelope. If the consciousness has left the body because of a demon or a sudden fright, for example, a ritual can be undertaken to "recall the soul." The Tibetan cultural border between death and the loss of consciousness is not tidy. The same linguistic usage has been reported among the Turkish-Mongolian people. In Bhutan a person may be called "dead" if he or she faints for a few minutes or loses consciousness at the end of a séance (Pommaret, 1989). Sicknesses such as epilepsy may also take one to the fuzzy border of death.

Nevertheless, these delogs may also lie unconscious for days with no food or drink, and return with remarkably detailed accounts of classic religious landscapes. The delogs may live in the peripheral areas of Bhutan, far from the main monasteries, and they deny having received any religious teachings, yet they recite detailed Buddhist chants. They all serve the bodhisattva Avilokiteshvara. After an initial traumatic illness, they "die" on traditional Buddhist days of fasting each month.

Secondly, Pommaret was one of the anthropologists who asked whether the delogs were enacting practices from very ancient tribal religious traditions, blending, almost obscuring them with Buddhist themes:

les 'das log sont-ils témoins inconscients d'un phénomène chamanique qui aurait été recuperé par le bhouddhisme au point d'oblitérer totalement son origine? [Are the delogs unconscious witnesses of a shamanic phenomenon which has been blended with Buddhism to the point of totally obliterating its origin?] (Pommaret, 1989, p. 153)

The widespread religious traditions now called "shamanism," going back to the dawn of culture, traditionally involve entering a trance, sometimes flirting with death, journeying to another realm, and returning with helpful information. Shamanism is a diverse, worldwide phenomenon, ranging from Australian aborigine to Siberian practices. Eliade's classic text documented widespread practices, including initiatory illnesses and suffering near death: "Sick with smallpox, the future 
[Siberian] shaman remained unconscious for three days and so nearly dead that on the third day he was almost buried" (Eliade, 1951, p. 39).

Death, descent to the underworld, and resurrection are central themes in shamanic traditions. The anthropologist Irving Hallowell (1940) studied the Algonkian Saulteaux in Canada and found numerous accounts of otherworld journeys and resuscitations of people supposed to be dead, usually of extraordinary spiritual powers. One native told him: "I saw a man who died and lay dead for two days" (Hallowell, 1940 , p. 30). He told of a journey where he met his deceased parents. Returning, he reported:

But even daylight here is not so bright as it is in the country I had visited. I had been lying for two days. But I had traveled a long distance in that length of time. It is not right to cry too much for our friends, because they are in a good place. They are well off there. So I'm going to tell everybody not to be scared about dying. (Hallowell, 1940, pp. 30-31)

Pommaret proposed that the Tibetan delogs are living evidence of the practice of archaic Himalayan shamanism, blended with Buddhism: "les'das log possèdent les critère essentiels d'un phénomène chamanique [the delogs possess the essential criteria of a shamanic phenomenon]" (1989, p. 161). William Serdahely agreed, reviewing a number of reports of shamans whose apparent deaths initiated them into their spiritual and healing powers: "it would seem that some shamans were near-death experiencers first" (Serdahely, 1991, p. 256).

Bringing these data to the quest to understand near-death experiences, we can see that contemporary NDEs have the marks of ancient shamanic traditions and are akin to them. Even though most Western survivors of NDEs may have no idea of the shamanic background to their experiences, the Tibetan delogs are a living bridge to this tribal past. This connection sheds new light on some problems of the interpretation of NDEs.

The debate over the definition of death and whether NDE survivors were actually dead can now point to the fuzzy border, the liminal range between life and death in shamanic tradition. Apparently shamans may enter into a light trance, a long, heavy trance, a long state of comatose unconsciousness, or a dramatic loss of life signs for some time, and still return to life. Heeding this phenomenon, the study of NDEs need not get blocked at the issue whether all the survivors were completely dead or experienced a "little death." We can study the state of consciousness itself, whether a trance, coma, or clinical death; and we can study the results, as a process, a fuzzy but meaningful alternative to conventional 
thinking that seeks dualistic precision on such matters. Death is a mysterious process, with many variations in consciousness, including ego death and bodily resuscitation.

Contemporary scholars of shamanic practices have acknowledged these connections between shamanism and NDEs. Anthropologist Michael Harner, the author of a classic study of shamanism (1980) who underwent shamanic initiations himself, agreed that "there is an overlap between shamanism and near-death experiences" (M. Harner, personal communication, June, 1997). Joan Halifax placed this theme in the larger context:

The shaman's initiation ... embraces the experience of death, resurrection and realization or illumination.... Variations on the fundamental themes of death and rebirth are found in all mythological traditions, and an encounter with death and release into rebirth are immutable dimensions of most personal religious experiences. (1979, p. 4)

The study of these experiences gives us a greater understanding not only of psychology, psychopathology and parapsychology, but also of near-death and mystical experiences. (1987, p. 217)

Clearly there is a strong overlap between NDEs and the delog experiences: out-of-body experiences, meeting others, the life review, the border or bridge to the other world, coming back, telling others, effects on lives, and new views of death. Survivors and students of NDEs can place their journeys into other worlds in the contexts of shamanic journeys, including the Tibetan delogs. Indeed, as Timothy Green suggested, "By developing the skill of shamanic journeying, NDErs could become shamanic healers" (1998, p. 209).

Three important themes-cultural, social scientific, and spiritualunderlie these discussions, complex issues that need further reflection. The cultural theme is the issue of cultural relativity. The delog literature, as well as the shamanic parallels, both raise the serious question of how much cultural variation points to total cultural relativism and how much the variation reflects only surface differences symbolizing deeper universals in all NDEs. Obviously shamanic and other soul journeys are shaped by their local cultural symbols, much as the delogs have absorbed Buddhist and Hindu cosmologies. The NDEs of Western industrialized cultures will likewise be influenced by their local cultural forms, including, for example, industrialism, Christianity, and psychoanalysis. The delog material gives evidence to the cultural relativists who would argue that the contemporary Euro-American picture of NDEs is neither a standard nor a universal pattern, nor is it the 
criterion or touchstone to which we should compare similar phenomena from other cultures. On the contrary, we should be acutely aware that our current eruption of NDEs is very strongly shaped by our culture, just as the others have been. Most radically, a relativist might argue that there is no single neutral pattern, no core, invariant NDE, whether industrial American or spiritual Tibetan. And the extreme relativist might conclude that these visions are cultural constructs made up from meaningless hallucinations and superstitious mythologies.

The social scientific theme involves interpretations of a common core beneath the cultural variants. Carr represented this view in his comparison between Tibetan and Euro-American NDEs. He agreed that "The shamanic journey has many analogs to the death process" (1993, p. 90). Carr noted many learned cultural differences, such as the Christian belief in forgiveness and peaceful Western NDEs, versus the fearfulness and the lack of dark tunnels in Tibetan visions; but he also saw more shared themes, such as the religious figures, the light, and a life review.Cultural relativism cannot explain the wealth of worldwide similarities (Carr, 1993).

The global phenomenology of NDEs and shamanic journeys is also supported by archetypal psychology, which points to worldwide appearances of symbolic invariant core experiences such as the light, the peace, the darkness, and local symbols of divinity, whether Jesus in the West or Buddha in the East (Yates, 1996). The key is to see the symbolism and avoid simplistic literal interpretations (Bailey, 1996). Epstein translated Tibetan delog texts and saw them as "fully consistent with the so-called classical shamanism of northern Asia" (1982, p. 60). Epstein was probably right that delogs as oracles and shamans are fringe elements in Tibetan culture and "are regarded historically by Tibetans as representing a stage of religious development surpassed and supplanted by, and morally inferior to, Buddhism" (1982, p. 61). I am unconvinced, however, by his further attempt to reduce the delog phenomena to "hallucinatory" (1982, p. 48) and "regressive" (1982, p. 73) instances of neoFreudian object-relations theory. I question his effort to reduce Avalokiteshvara to a mere "model of the maternal imago" (1982, p. 71) and the Lord of the Dead as the punishing superego, "an Oedipal figure par excellence" (1982, p. 72). In this schema, the delog's spiritual activity would be nothing but unconscious, infantile efforts to "reparent" others, in good Freudian style (Epstein, 1982). While such unconscious elements may be partly relevant, this interpretation risks becoming an ethnocentric projection of a Western neoFreudian theory, and an unnecessarily reductive denial of this religion. 
On the other hand, psychoanalysis in general has positively influenced the theoretical context for interpreting NDEs by demonstrating through psychotherapy the reality and meaningfulness of the unconscious psyche. Taking the reality of unconscious images seriously is an essential first step in placing near-death phenomena in an interpretive framework that goes beyond the scientific, industrial cultural vision of literal truth, and adding to the discussion the realm of paradoxical and symbolic language.

In addition, Freud strengthened psychoanalysis with the scientific practice of withholding judgment. This judgment-withholding element of Western culture seems to have influenced NDEs themselves. Most contemporary Western NDErs do not encounter a fearful Lord of the Dead judging harshly, or nasty devils punishing sadistically. They are more likely to meet a kindly counselor who asks: "What have you learned in your life?" This is not fearful religious moralism, but thoughtful soul healing.

Our culture has passed our medieval stage of development and instituted mass education. This indoctrinates the masses with the basic rational and moral expectations of our civilization, so religion is not needed as much to scare us into behaving decently, although the capacity of mass education to reduce 20th century violence has been sadly limited. A new spiritual education and motivation is also needed. NDEs reflect our culture's type of consciousness, in which educated people do not respond well to a religious vision based on fear. NDEs, shamans, and delogs in different cultures will seem radically different, but they do reveal archetypal similarities reaching over vast ages and distances: the light takes many forms.

Finally, there is an underlying spiritual theme that needs to be addressed. The NDE phenomenon, delog visions, and shamanic journeys are spontaneous expansions far beyond our normal consciousness. These events are part of the postmodern questioning of the universal validity of the industrial ego. Industrialism promotes ego-consciousness, self-control, will, reason, logic, and materialism, but NDEs imply a fuzzy border between life and death, consciousness and unconsciousness, certainty and uncertainty, truth and falsehood. Echoing Buddhist themes, NDE-like phenomena often present themselves as revelations of a divine oneness in the universe that holds life and death in its amazing embrace. NDEs are a postindustrial, postmodern conundrum expanding Western consciousness beyond the narrow, shaky certainties of industrial consciousness and its associated traditional religions. We are witnesses of the awakening of a new spirituality, a healing global 
deepening of soul that needs to blend the best of scientific thinking with the best of mystical spirituality.

\section{References}

Alighieri, D. (1939). The divine comedy: Inferno, purgatorio, paradisio (Sinclair, J.D., Trans.). New York, NY: Oxford University Press. (Original work published 14th century)

Bailey, L. (1996). The no-thing-ness of near-death experiences. In Bailey, L., and Yates, J. (Eds.), The near-death experience: A reader (pp. 385-402). New York, NY: Routledge.

Bailey, L., and Yates, J. (1996). The near-death experience: A reader. New York, NY: Routledge.

Blofeld, J. (1970). The tantric mysticism of Tibet. New York, NY: Dutton.

Carr, C. (1993). Death and near-death: A comparison of Tibetan and Euro-American experiences. Journal of Transpersonal Psychology, 25, 59-110.

Brinkley, D., and Perry, P. (1994). Saved by the light: The true story of a man who died twice and the profound revelations he received. New York, NY: Villard.

Drolma, D. D. (1995). Delog: Journey to realms beyond death (Barron, R., Trans.). Junction City, CA: Padma Publishing.

Eliade, M. (1951). Shamanism: Archaic techniques of ecstasy. Princeton, NJ: Princeton University Press.

Epstein, L. (1982). On the history and the psychology of the 'das-log. Tibet Journal, 7(4), $20-85$.

Gibbs, J. (1997). Surprise-and discovery?-in the near-death experience. Journal of Near-Death Studies, 15, 259-278.

Govinda, L. A. (1960). Foundations of Tibetan mysticism. New York, NY: Samuel Weiser.

Green, J. T. (1998). Near-death experiences, shamanism, and the scientific method. Journal of Near-Death Studies, 16, 205-222.

Halifax, J. (1979). Shamanic voices: A survey of visionary narratives. New York, NY: Arkana/Penguin.

Halifax, J. (1987). Shamanism, mind, and no-self. In Nicholson, S (Ed.), Shamanism: An expanded view of reality. Wheaton, IL: Quest Books.

Hallowell, A. I. (1940). Spirits of the dead in Saulteaux life and thought. Journal of the Royal Anthropological Institute, 70, 29-51.

Harner, M. (1980). The way of the shaman: A guide to power and healing. New York, NY: Harper and Row.

Pommaret, F. (1989). Les revenants de l'au-dela dans le monde Tibetain: Sources littéraires et tradition vivante [Those who return from the hereafter in the Tibetan world: Liter. ary sources and living tradition]. Paris: Editions du Centre National de le Recherche Scientifique.

Powers, J. (1995). Introduction to Tibetan Buddhism. Ithaca, NY: Snow Lion.

Ring, K. (1993). A new book of the dead: Reflections on the near-death experience and the Tibetan Buddhist tradition regarding the nature of death. Journal of Near-Death Studies, $12,75-84$.

Serdahely, W. (1991). Were some shamans near-death experiencers first? Journal of NearDeath Studies, 9, 255-257.

Sharp, K. C. (1995). After the light: What I discovered on the other side of life that can change your world. New York: Morrow.

Sogyal Rinpoche. (1993). The Tibetan book of living and dying. San Francisco: HarperSanFrancisco.

Thurman, R. A. F. (Trans.). (1994). The Tibetan book of the dead. New York, NY: Bantam. 
Thimphu. (1980). Excellente biographie de la révérende revenante de l'au-delà Sangs rgyas chos 'dzom, incarnation de'Avalokiteshvara. Y est recontèe l'histoire de sa visite des enfers, en bas, et des paradis, en haut, pendant sept jours. [Excellent biography of the holy woman who returned from the beyond, Sangs Rgyas chos 'dzom, incarnation of Avalokiteshvara. Here is told the story of her visit to hell, below, and paradise, above, for seven days.]

Yates, J. (1996). Being of light: dreaming the vision onward. In Bailey, L., and Yates, J. (Eds.), The near-death experience: A reader (pp. 145-155). New York, NY: Routledge.

Zaleski, C. (1987). Otherworld journeys: Accounts of near-death experience in medieval and modern times. New York, NY: Oxford University Press. 